\title{
Juan Ortiz Escamilla, Calleja. Guerra, botín y fortuna, Universidad Veracruzana/El Colegio de Michoacán, México, 2017, ISBN: 978-607- 502-602-2 (UV), ISBN 978-607-9470-93-7 (COLMICH), pp. 271.
}

Copyright: $\odot$ 2020. Navarro, J. Este es un artículo de acceso abierto, distribuido bajo los términos de la licencia https://creativecommons.org/licenses/by-nc$\underline{\mathrm{sa} / 4.0 / \text { la cual permite el uso sin restricciones, }}$ distribución y reproducción en cualquier medio, siempre y cuando que el original, el autor y la fuente sean acreditados.

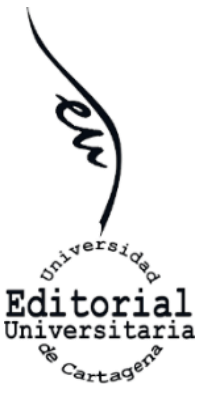

En el oficio de Clío, la biografía representa uno de los géneros históricos que más fascinan y deslumbran a los lectores. La vida de los individuos normales y excepcionales se convierte en un faro de múltiples experiencias que deslumbran y develan las realidades históricas de los biografiados y como dice François Dosse: "sacar todo a la luz es, por tanto, a la vez la ambición que guía al biógrafo y una aporía que lo condena al fracaso". ${ }^{1}$

Este dilema se le presentó a Juan Ortiz Escamilla en la obra de la que se ocupa esta reseña, se trata de una biografía histórica de Félix María Calleja del Rey, la obra de la autoría de Juan Ortiz Escamilla, coeditada por la Universidad Veracruzana y El Colegio de Michoacán, es un estudio acerca de la vida, los negocios, el botín, así como la fortuna que obtuvo Calleja a lo a largo de su carrera militar en las tierras de la Nueva España en los periodos que van desde la reforma hasta la independencia e incluso más allá.

Calleja fue un hombre que despertó debates en su época y aún en la actualidad su nombre resulta escabroso para ciertos sectores de la sociedad mexicana es un interesante punto de partida, pues la recuperación de la vida de los individuos olvidados y tachados de la historiografía es fundamental para acercarnos a una comprensión crítica de nuestra historia. El autor dice en su justificación atinadamente que al ser "la historia un campo de realidades y no de mitos" (p. 14), la vida y la obra de Félix María Calleja, sin lugar a duda, requiere un lugar real fuera de la mitificación, ya que, como ser histórico de su tiempo, expone y revela las facetas de los militares de su época.

Este trabajo se encuentra dividido en cuatro capítulos titulados: "El militar ilustrado, El estratega militar en la contrainsurgencia, La política como continuación de la guerra y La fortuna del conde de Calderón", y claro las reflexiones finales, que van revelando atinadamente la vida de Calleja, un hombre que se ilustró en la península, que forjó su fama militar en los conflictos continentales que España mantuvo y que mantuvo cercana relación con los militares que harían fama en la América.

El militar ilustrado. Félix María Calleja del Rey formó parte de la generación de oficiales del ejército realista español educada bajo los principios y los cánones del llamado despotismo ilustrado francés; era una oficialidad preparada para servir a la Corona en cualquiera de las tareas que se le encomendasen, bien fuera peleando en los campos de batalla $o$

${ }^{1}$ François Dosse, El arte de la biografía, Universidad Iberoamericana, México, 2011, p. 25 
ejerciendo puestos como visitador, virreyes, gobernadores o auditores de la Real Hacienda, entre otros. (p. 17).

La obra comienza de forma directa, estableciendo la realidad de Calleja la cual va desde el nacimiento hasta su ingreso al real servicio de las armas. Juan Ortiz enfatiza el lugar de origen, el estatus social al que pertenencia y como toda obra histórica, va intercalando entre la nota historiográfica y la apostilla archivística, lo cual, va mostrando a un Calleja hecho y curtido en el campo de batalla, la realidad de Félix, así como la de muchos de sus coetáneos, es decir, la oficialidad realista, fue la guerra, la campaña militar y los cañonazos:

Gibraltar se convirtió en la escuela donde se formaron y foguearon, en el arte de la guerra, la mayor parte de los virreyes y oficiales reales que al final del periodo colonial viajaron a América. Por dar un ejemplo, en el sitio Calleja convivió con futuros virreyes de América, como el segundo conde de Revillagigedo, Miguel de la Grúa Talamanca y Branciforte, Santiago de Liniers y Francisco Xavier Venegas, éste, su antecesor, ya tenía experiencia en la batalla. (p. 21).

Es interesante que dentro de la documentación que se usa para perfilar a Calleja, Juan Ortiz destaca la implementación de los archivos militares como: los del Archivo del Servicio Histórico Militar de España, el Archivo Histórico Militar de Madrid, entre otros repositorios castrenses como el Archivo General Militar de Segovia, destacando que de esta manera el autor fija afirmaciones varias respecto a la juventud del personaje y así mismo sus órdenes como "Visitador y espía" en la Nueva España. Este enfoque archivístico muestra el principal interés de la biografía, la carrera militar del personaje.

Juan Ortiz Escamilla logra definir o, mejor dicho, redefine a un hombre cuyas acciones militares desdibujan la historia oficial. Es atrayente que el autor no sólo aborde elementos contextuales, sino que va más allá y logra entablar un discurso sobre el uso de la categoría: "guerra", la cual muchas veces queda difuminada cuando hablamos sobre procesos como el que se llevó a cabo en la Nueva España. Con respecto a ello el autor menciona que le "parece un eufemismo utilizar conceptos como 'procesos de emancipación', 'ciclos revolucionaros', 'revoluciones hispánicas', sin considerar el significado de la guerra o por lo menos que se le tenga presente" (p. 248).

Calleja. Guerra, botín y fortuna, atrapa el interés del lector pues como hemos dicho, dibuja a un hombre forjado en la crueldad de la guerra y es en los campos de la batalla donde brilla el libro, ya que bajo la revisión de estos pasajes, es donde notamos un punto de vista distinto sobre figura tan controversial y es que: "Calleja no ignoraba los motivos que habían dado origen a la revolución; era un hombre ilustrado, sin embargo, para un militar de profesión, como él, su misión era sostener al monarca español en estas tierras, sin importar el costo humano y económico" (p. 73).

Es notorio que el libro no sólo se limita a una mirada militar de la vida de Calleja, el autor entabla un atinado balance con respecto a la construcción de las relaciones sociales, es decir, desde su unión conyugal con María Francisca de la 
Gándara y la acumulación de riquezas a partir de sus empresas en el septentrión novohispano. Es de suma notoriedad que en los confines norteños virreinales los negocios que forjó Félix derivaron en fructíferas empresas cuya rentabilidad superaba con creses los salarios que habitualmente tenían los militares, sus negocios principalmente se orientaron a la cría de ganado desde caballar hasta caprino.

La insurgencia y el movimiento liderado por el cura Hidalgo pronto azotó los corazones de los novohispanos, los miedos y temores fueron francos, así como la pronta necesidad de frenar a los combatientes.

Desde el inicio de la rebelión él identificó dos tipos de insurgentes: los que luchaban por convicción y decididos a derrocar al gobierno, y aquellos a los que la rebelión había arrastrado contra su voluntad por residir en las poblaciones en que se libraban los enfrentamientos. Según Calleja, a los primeros no les quedaba otra alternativa más que la horca, y a los segundos habría que ofrecerles la gracia del indulto. (p. 79)

Es en este apartado donde Juan Ortiz dedica con ahínco una visión diferente al proceso de la guerra y es que, en la medida de lo posible, el autor va estableciendo el contexto desde la perspectiva militar realista y no insurgente, destacando no sólo las batallas y los encontronazos, sino enfatiza en la visión estratégica y política que tenía Calleja. Esta visión se plasma en dos momentos cruciales, el primero, previo a la batalla del puente de Calderón, donde al mando de 4000 efectivos Félix junto con el estado mayor del Ejército del centro analizan su posición y la situación del enemigo. Y el segundo, bajo la elaboración del llamado "Plan Calleja", Un plan de gobierno "que generalizó la participación de la población civil en el proceso de pacificación” (p. 95).

Juan Ortiz recupera la exitosa política que implementó Calleja con su plan militar y también rememora las icónicas batallas no sólo en su desarrollo, sino en la implementación de las tácticas y el desgaste humano que significo esto, todo ello aunado al éxito de sus relaciones sociales le permitió acceder al puesto de virrey, pues los méritos, la efectividad y claro las tendencias políticas, formaron la dirección de su asenso político.

Calleja no derrotó a la insurgencia por la vía de las armas como se ha creído; lo hizo por medios de diversas estrategias que incluyeron aspectos políticos. A partir del 4 de marzo de 1813, día en que asumió el gobierno virreinal en la Ciudad de México, Calleja mostró también sus habilidades como político y negociador en un momento coyuntural debido a que las instituciones coloniales mostraron gran inestabilidad y entraron en crisis (p. 111).

La pacificación y el restablecimiento del orden fueron dos aspectos que tuvieron la prioridad de la administración de Calleja, en la obra, Juan Ortiz enfatiza la eficacia de gestión y la política que fue elaborando con la finalidad de parar la insurrección. "El gobierno promovió una intensa campaña de información para 
ilustrar la opinión de estos habitantes en las materias de su mayor interés, y persuadirlos de la generosidad del legítimo gobierno" (p. 114).

A nuestro criterio son muchos los aspectos que va cubriendo la obra sobre la participación de Calleja como general de los Ejércitos del centro, es innegable la gran documentación de la cual se nutre el libro, no se diga a la hora de hablar de la práctica política que se fue gestando bajo su administración. Pero sin dudas uno de los intereses del autor es ir develando las riquezas que mantuvo el conde de Calderón y la forma que la fue incrementado a lo largo de su estancia en la Nueva España. Resulta sumamente benéfico el entablar el discurso económico en la construcción biográfica del personaje, pues ayuda a dilucidar la riqueza y la opulencia a la que el individuo mantenía. Así pues, el autor presenta diversos cuadros que ayudan a entender los bienes y las riquezas que logro acumular Calleja, pues como afirma Juan Ortiz:

Si partimos de la norma jurídica que prohibía a los militares en activo hacer cualquier tipo de negocios personales, no deja de impresionar la fortuna reunida por Calleja durante los 27 años que vivió en la Nueva España, de 1789 a 1816. También llama la intención la manera de evadir la justicia (para Yovana Celaya era una simple estrategia para la movilización de recursos de capital), tanto cuando hubo que registrar su fortuna ante el escribano de guerra como, ya después de su muerte, cuando el comisario de guerra revisó el inventario de los bienes del difunto.

Es claro que esta obra es buena y la documentación en la que se basa es invaluable para los estudiosos del periodo y de los militares, nos encontramos con un modelo histórico que se puede emplear para otros individuos. No obstante, nos hubiera gustado que la obra enfocara algunos aspectos netamente familiares, más allá de las menciones que realiza de la unión conyugal que mantuvo con María Francisca de la Gándara, así mismo, la lectura arroja una importante librería que Calleja testamentó, enfocarse en esto nos hubiera brindado una importante visión acerca de sus hábitos y pasión intelectual, pero comprendemos que no es la finalidad del libro.

Calleja. Guerra, botín y fortuna, de Juan Ortiz Escamilla es una obra cuya lectura es obligatoria, no sólo por la enorme dimensión del personaje histórico tan controversial, sino porque su recuperación histórica es un invaluable agregado a las nuevas formas de entender la historia de la guerra de independencia mexicana $\mathrm{y}$ a sus actores.

José María Navarro Méndez.

Licenciado en Historia

Universidad Michoacana de San Nicolás de Hidalgo Maestro en Historia por la Universidad Autónoma de Sinaloa (UAS) Doctorante en Historia por la UAS. josenavarro517@gmail.com 